\title{
SCARF syndrome
}

INSERM

\section{Source}

INSERM. (1999). Orphanet: an online rare disease and orphan drug data base. SCARF syndrome. ORPHA:3134

SCARF syndrome is characterised by the association of skeletal abnormalities, cutis laxa, craniostenosis, ambiguous genitalia, psychomotor retardation and facial abnormalities.

So far, it has been described in two males (maternal first cousins). The mode of inheritance was suggested to be X-linked recessive. 